\title{
In vitro and in vivo plasmalogen replacement evaluations in rhizomelic chrondrodysplasia punctata and Pelizaeus-Merzbacher disease using PPI-1011, an ether lipid plasmalogen precursor
}

Paul L Wood ${ }^{1 *}$, M Amin Khan ${ }^{2}$, Tara Smith², Greg Ehrmantraut ${ }^{2}$, Wei Jin², Wei Cui ${ }^{3}$, Nancy E Braverman ${ }^{3}$ and Dayan B Goodenowe ${ }^{2}$

\begin{abstract}
Background: Childhood peroxisomal disorders and leukodystrophies are devastating diseases characterized by dysfunctional lipid metabolism. Plasmalogens (ether glycerophosphoethanolamine lipids) are decreased in these genetic disorders. The biosynthesis of plasmalogens is initiated in peroxisomes but completed in the endoplasmic reticulum. We therefore undertook a study to evaluate the ability of a 3-substituted, 1-alkyl, 2-acyl glyceryl ether lipid (PPI-1011) to replace plasmalogens in rhizomelic chrondrodysplasia punctata type 1 (RCDP1) and rhizomelic chrondrodysplasia punctata type 2 (RCDP2) lymphocytes which possess peroxisomal mutations culminating in deficient plasmalogen synthesis. We also examined plasmalogen synthesis in Pelizaeus-Merzbacher disease (PMD) lymphocytes which possess a proteolipid protein-1 (PLP1) missense mutation that results in abnormal PLP1 folding and it's accumulation in the endoplasmic reticulum (ER), the cellular site of the last steps in plasmalogen synthesis. In vivo incorporation of plasmalogen precursor into tissue plasmalogens was also evaluated in the Pex7 mouse model of plasmalogen deficiency.

Results: In both RCDP1 and RCDP2 lymphocytes, PPI-1011 repleted the target ethanolamine plasmalogen (PIsEtn16:0/22:6) in a concentration dependent manner. In addition, deacylation/reacylation reactions resulted in repletion of PIsEtn 16:0/20:4 in both RCDP1 and RCDP2 lymphocytes, repletion of PlsEtn 16:0/18:1 and PlsEtn 16:0/ 18:2 in RCDP2 lymphocytes, and partial repletion of PlsEtn 16:0/18:1 and PlsEtn 16:0/18:2 in RCDP1 lymphocytes. In the Pex7 mouse, oral dosing of labeled PPI-1011 demonstrated repletion of tissue levels of the target plasmalogen PIsEtn 16:0/22:6 with phospholipid remodeling also resulting in significant repletion of PIsEtn 16:0/20:4 and PlsEtn 16:0/18:1. Metabolic conversion of PPI-1011 to the target plasmalogen was most active in the liver.

Conclusions: Our data demonstrate that PPI-1011 is activated (removal of 3-substitution) and converted to PIsEtn in vitro in both RCDP1 and RCDP2 lymphocytes and in vivo in the Pex7 mouse model of RCPD1 effectively bypassing the peroxisomal dysfunction present in these disorders. While PPI-1011 was shown to replete PlsEtns 16:0/x, ether lipid precursors of PIsEtn 18:0/x and PIsEtn 18:1/x may also be needed to achieve optimal clinical benefits of plasmalogen replacement in these complex patient populations. In contrast, only limited plasmalogen replacement was observed in PMD lymphocytes suggesting that the effects of protein misfolding and accumulation in the ER negatively affect processing of plasmalogen precursors in this cellular compartment.
\end{abstract}

Keywords: Rhizomelic chrondrodysplasia punctata type 1, Rhizomelic chrondrodysplasia punctata type 2, PelizaeusMerzbacher disease, Pex7 mouse, lymphocytes, plasmalogen precursor, DHA, peroxisomal disorders, PPI-1011

\footnotetext{
* Correspondence: paul.wood@lmunet.edu

'Dept. of Pharmacology, DeBusk College of Osteopathic Medicine, Lincoln Memorial University, 6965 Cumberland Gap Parkway, Harrogate, TN, 37752, USA

Full list of author information is available at the end of the article
} 


\section{Background}

The peroxisome disorder, rhizomelic chrondrodysplasia punctata (RCDP) is a devasting disease characterized by severe growth retardation and developmental delays. Most children do not survive beyond 10 years of age and death is often secondary to respiratory illnesses [1]. The clinical features of RCDP are a direct result of plasmalogen deficiency. Two peroxisomal enzymes, acyl CoA:dihydroxyacetonephosphate acyltransferase (GNPAT; EC 2.3.1.42) and alkyl-dihydroxyacetone phosphate synthase (AGPS; EC 2.5.1.26), are critical for the committing steps of ether lipid plasmalogen synthesis [2]. RCDP is a heterogeneous autosomal recessive disorder [3-5] most commonly caused by defects in the PEX7, the peroxisome transporter for AGPS (RCDP1), but also by defects in the enzymes themselves, GNPAT, (RCDP2) or AGPS (RCDP3). After synthesis of alkylglycerol precursors in the peroxisome, the synthesis of ether phospholipids are completed in the ER. Nevertheless, the only known inherited defects in plasmalogen synthesis are the peroxisomal defects.

Recently, we performed a lipidomics analysis [6] in Pelizaeus-Merzbacher disease (PMD) fibroblasts and lymphocytes [7-9], in which we demonstrated significant reduction in plasmalogen levels. However the etiology for this plasmalogen deficiency is unknown.

Since there are no treatments for these disorders, we undertook an evaluation of the ability of PPI-1011, a DHA-containing ether lipid plasmalogen precursor which bypasses the requirement for peroxisomes, to augment deficient cellular plasmalogens in RCDP1, RCDP2 and PMD lymphocytes and in the murine Pex7 model of RCDP1 [10].

\section{Materials and methods Cell Culture}

Control lymphocytes (Coriell GM13072 and GM02184); PMD lymphocytes (Coriell GM09545; PLP1 c.767C > T or p.P215S); RCDP1 lymphocytes (Coriell GM09291; PEX7 c.870 871insCAA/875T > A or p.C290 E291insQ/ L292X and show a severe plasmalogen synthesis defect) and RCDP2 lymphocytes (Coriell GM16776; homozygous for GNPT c.1280-3T > G predicted to encode an in-frame protein p.427 507 del and showing a milder plasmalogen synthesis defect) [11] were kept as suspension cultures (25 ml flasks) in RPMI 1640 (Hyclone) supplemented with $10 \%$ FBS and $1 \%$ antibiotic/antimycotic, at $37^{\circ} \mathrm{C}$ in a $5 \% \mathrm{CO}_{2}$ incubator [6].

Lymphocytes were harvested $(1280 \times \mathrm{g})$ and washed twice with cold phosphate buffered saline (PBS) and the stored at $-80^{\circ} \mathrm{C}$ for subsequent lipidomic analyses.

\section{Plasmalogen Synthesis}

To monitor plasmalogen synthesis lymphocytes were incubated with 20 or $100 \mathrm{uM}$ PPI-1011 [7,12] or PPI-
1038 for $72 \mathrm{hr}$ and incorporation into cellular plasmalogens measured. PPI-1038 is a stable isotopic version of PPI-1011, an ether lipid plasmalogen precursor with a $\left[{ }^{13} \mathrm{C}_{3}\right]$ glycerol backbone $(\mathrm{G})$, a $\left[{ }^{13} \mathrm{C}_{16}\right]$ palmitic ether linkage (P) at sn-1, a $\left[{ }^{13} \mathrm{C}_{3}\right]$ DHA (D) acyl linkage at sn-2, and a lipoic acid acyl linkage at sn-3 to stabilize the precursor. Incorporation into the target plasmalogen was monitored as $\left[{ }^{13} \mathrm{C}_{22}\right]$ 16:0/22:6 PlsEtn (P-G-D). Lipid remodeling, which involves deacylation at sn-2 (i.e. removal of $\left.\left[{ }^{13} \mathrm{C}_{3}\right] \mathrm{DHA}\right)$ and reacylation with other fatty acids was monitored as $\left[{ }^{13} \mathrm{C}_{19}\right] 16: 0 / x$ PlsEtns (P-G). Acylation of unlabelled plasmalogen precursors with the released $\left[{ }^{13} \mathrm{C}_{3}\right]$ DHA was monitored as $\left[{ }^{13} \mathrm{C}_{3}\right] \mathrm{x} / 22: 6$ PlsEtns (D). The specificity of these measurements was achieved via specific LC-MS/MS MRMs.

\section{Pex7 Mice}

Levels of plasmalogens in different tissues were measured in Pex7 (18 to 24 g) mice [10] and both heterozygote and wild-type controls (24-30 g). No differences in plasmalogen levels were noted between wild-type and heterozygote controls. In the subsequent experiment, Pex7 mice and heterozygote controls were orally dosed by gavage with PPI-1038 (100 mg/kg; 10 mg/ml Neobee M5; Spectrum Chemical Mfg.) daily for 3 days. On day 4, tissues were harvested for plasmalogen analysis. All mice were studied between ages 2 and 3 months. The mouse studies were conducted under the McGill University Animal Care Committee approved protocol 5538 entitled "Study of PEX7 deficient mice as models for RCDP".

\section{Plasmalogen Analyses}

For plasmalogen analyses, cells or pulverized tissues were sonicated in $1 \mathrm{~mL}$ of PBS $+0.5 \mathrm{~mL}$ methanol. Next, $2 \mathrm{~mL}$ tert-butylmethylether were added and the samples capped and shaken (1400 rpm) for $10 \mathrm{~min}$ at room temperature. The samples were then centrifuged for $8 \mathrm{~min}$ in a clinical centrifuge and $1 \mathrm{ml}$ of the upper organic layer isolated for LC-MS/MS analyses of endogenous and labeled ethanolamine plasmalogens as reported previously $[7,12-14]$.

\section{Data Analyses}

In vitro data are presented as mean \pm SEM for groups of six to eight $25 \mathrm{ml}$ flasks. Since standards are not available for the lipidomic analysis of diverse plasmalogens, these were normalized to the housekeeping metabolite PtdEtn 16:0/18:0. Data were analyzed by 1-way ANOVA, followed by the Tukey-Kramer test to determine differences between groups.

In vivo data are presented as mean \pm SEM for groups of 6 for plasmalogen levels and as mean \pm SD for groups of 4 mice for the precursor labeling study. HO comparisons to HT mice were conducted with a t-test. 


\section{Results}

Ethanolamine Plasmalogens in RCDP Lymphocytes In RCDP1 lymphocytes, PlsEtns $16: 0 / x$ were all decreased to approximately $25 \%$ of control (Figure 1). The ether lipid plasmalogen precursor, PPI-1011 effectively restored PlsEtn 16:0/22:6 and PlsEtn 16:0/22:4 and partially restored PlsEtn 16:0/18:2 and PlsEtn 16:0/18:1 (Figure 1).

In RCDP2 lymphocytes PlsEtns 16:0/x were all decreased to approximately $60 \%$ of control (Figure 1 ). All plasmalogens were augmented beyond control levels with PPI-1011 treatment (Figure 1).

In both RCDP1 and RCDP2 lymphocytes, PPI-1011 did not augment PlsEtns 18:0/x or PlsEtns 18:1/x (data not shown).

Ethanolamine Plasmalogen Synthesis in RCDP and PMD Lymphocytes

Incorporation of intact labeled (P-G-D $=\left[{ }^{13} \mathrm{C}_{16}\right]$ Palmitate- $\left[{ }^{13} \mathrm{C}_{3}\right]$ Glycerol- $\left[{ }^{13} \mathrm{C}_{3}\right]$-DHA) and remodeled (P-G)

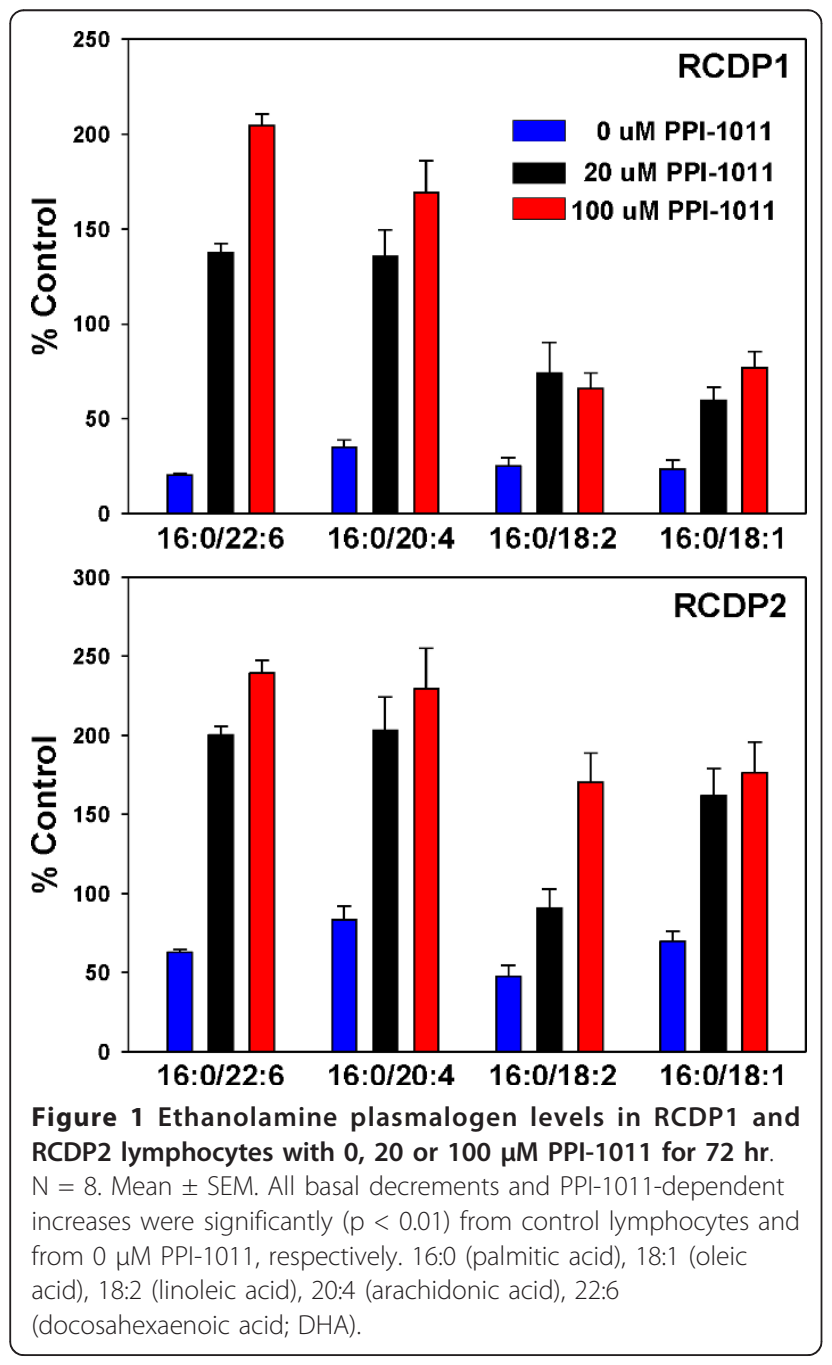

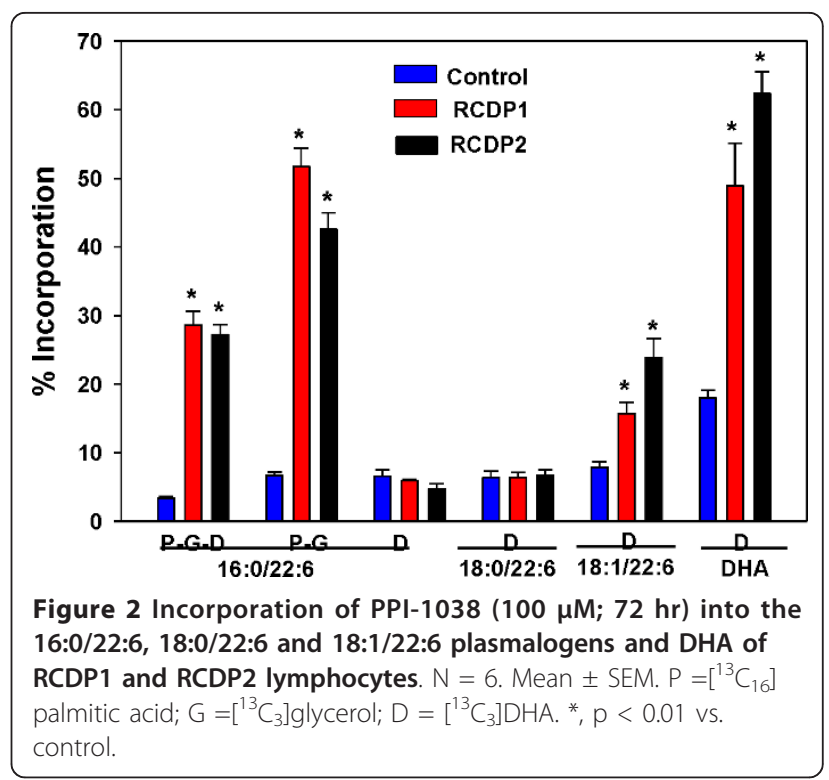

PPI-1038, into the target plasmalogen (PlsEtn 16:0/22:6) was significantly increased in both RCDP1 and RCDP2 lymphocytes (Figure 2). The labeled DHA pool formed by deacylation at sn-2 was significantly increased in both RCDP1 and RCDP2 lymphocytes (Figure 2). However, increased utilization of this DHA pool for reacylation at sn-2 was only observed in PlsEtn 18:1/22:6 (Figure 2).

Incorporation of intact labeled (P-G-D) and remodeled (P-G) PPI-1038, into the target plasmalogen (PlsEtn 16:0/22:6) was significantly increased in PMD lymphocytes (Figure 3), but much less than that observed with RCDP lymphocytes (Figure 2).

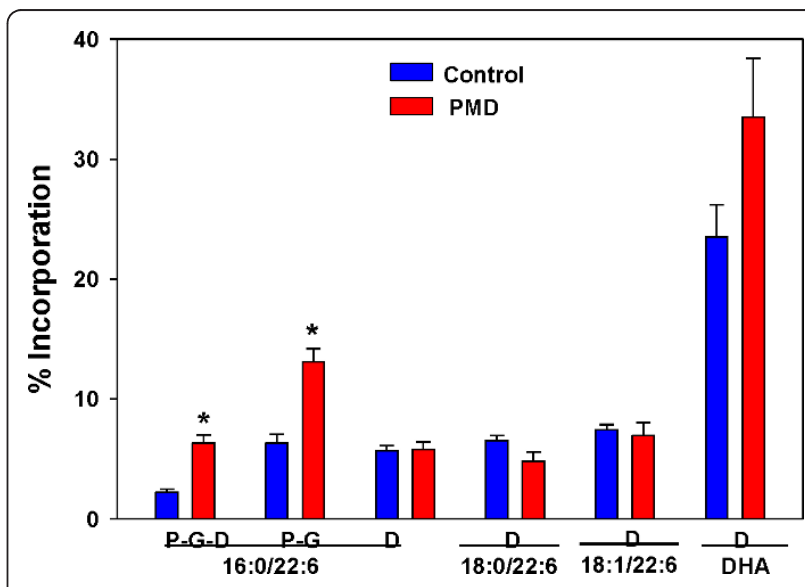

Figure 3 Incorporation of PPI-1038 (100 $\mu \mathrm{M} ; 72 \mathrm{hr})$ into the 16:0/22:6, 18:0/22:6 and 18:1/22:6 plasmalogens and DHA of PMD lymphocytes. $N=6$. Mean \pm SEM. $P=\left[{ }^{13} C_{6}\right]$ palmitic acid; $G=$ $\left[{ }^{13} C_{3}\right]$ glycerol; $D=\left[{ }^{13} C_{3}\right] D H A$. *,$p<0.01$ vs. control. 


\section{Pex7 Mice}

Tissue levels of PlsEtns 16:0/x were significantly decreased in the liver, kidneys, heart, lungs, neocortex and eyes of Pex7 mice (Figure 4). These decreases were approximately 50\% except for PlsEtns 16:0/22:6 and $18: 0 / 22: 6$ which were reduced to 15 to $30 \%$ of control in the eye and neocortex (Figure 4).

Administration of PPI-1038, daily for 3 days, resulted in significant labeling of the PlsEtn 16:0/22:6 pool in all tissues. The major labeled form in the adrenal, kidney, lung and liver was the $\left[{ }^{13} \mathrm{C}_{16}\right]$ palmitic acid $+\left[{ }^{13} \mathrm{C}_{3}\right]$ glycerol labeled PlsEtn 16:0/22:6, resulting from lipid remodeling at sn-2. The data for the adrenal, kidney and lung are presented in Figure 5. Much greater labeling in the liver was observed: $24.9 \pm 3.1 \%$ for heterozygote controls and $40.3 \pm 4.4 \%$ for homozygote Pex7 mice. In the case of the brain (neocortex) and eyes, increased $\left[{ }^{13} \mathrm{C}_{16}\right]$ palmitic acid $+\left[{ }^{13} C_{3}\right]$ glycerol labeled PlsEtn 16:0/22:6 was measured (Figure 6). In these tissues, the $\left[{ }^{13} \mathrm{C}_{3}\right] \mathrm{DHA}$ released by deacylation at $\mathrm{sn}-2$ was incorporated into

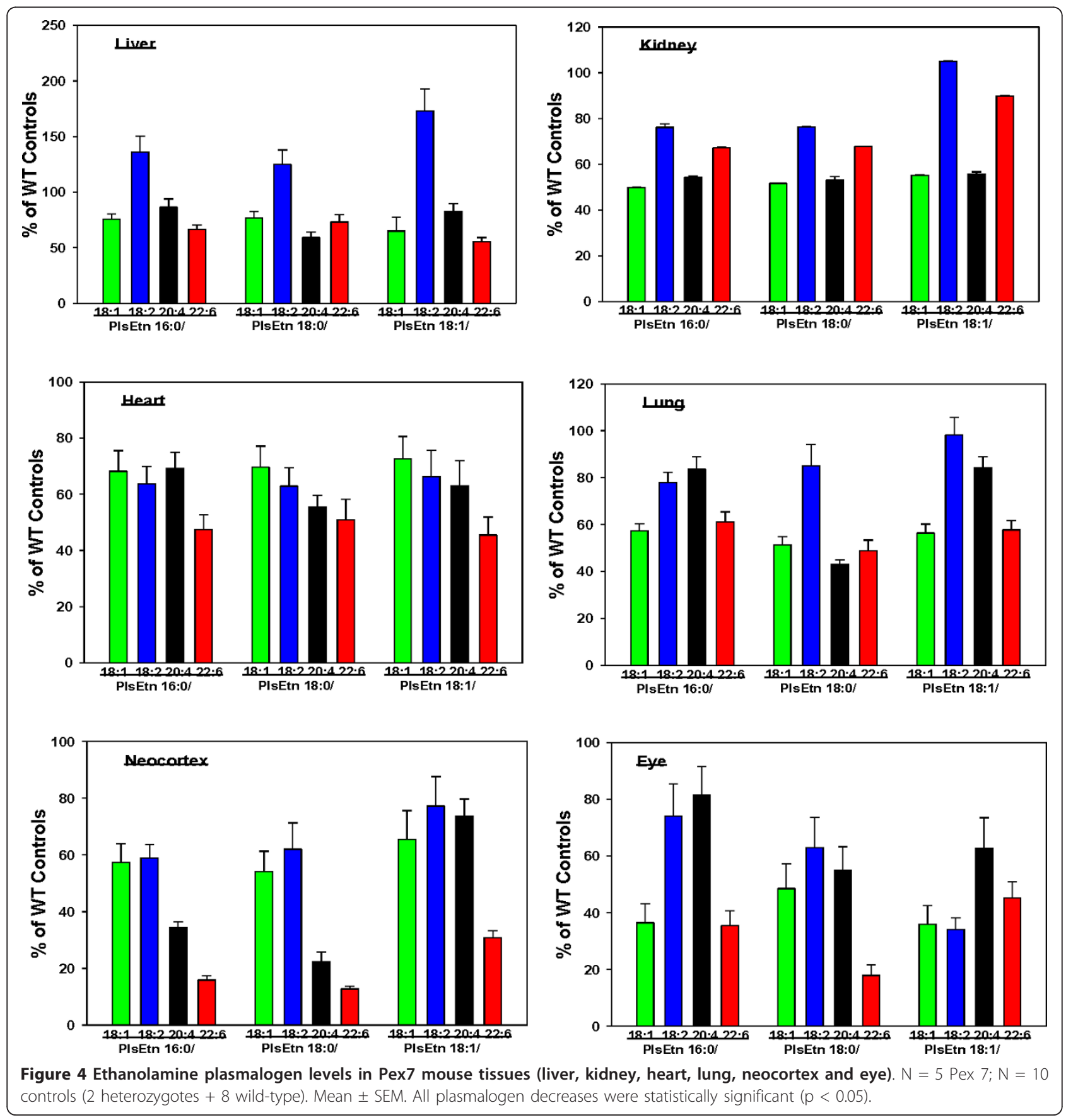




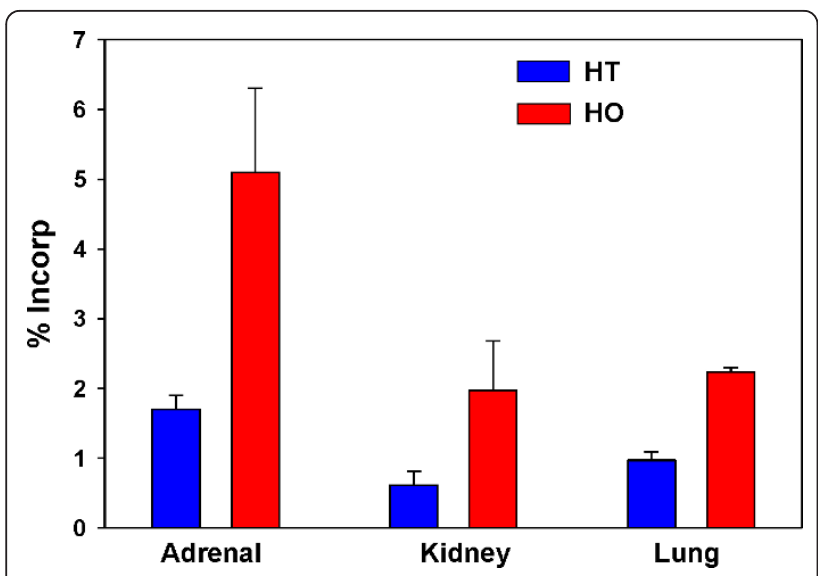

Figure 5 Incorporation of $\left[{ }^{13} C_{16}\right]$ palmitic acid and $\left[{ }^{13} C_{3}\right]$ glycerol from PPI-1038 (100 mg/kg/day for 3 days) into Pex7 tissue PIsEtn 16:0/22:6. $N=4$. Mean \pm SD. Increases in labeling in the Pex7 mice were significant in all cases $(p<0.01)$. HT, heterozygote controls; $\mathrm{HO}$, homozygotes.

PlsEtn 16:0/22:6, PlsEtn 18:0/22:6 and PlsEtn 18:1/22:6 (Figure 6).

\section{Discussion}

RCDP is a lethal disorder of critical peroxisomal genes involved in ether lipid synthesis, particularly ethanolamine plasmalogens (PlsEtn). Strategies to replace plasmalogens must take these deficiencies into account and supply ether lipid precursors that are capable of bypassing abnormal peroxisomal function. Our data demonstrate that PPI-1011 can bypass the requirements for functional peroxisomes since PPI-1011 efficiently replaced the target PlsEtn 16:0/22:6 (Figure 7) in both RCDP1 and RCDP2 lymphocytes. In addition, this target plasmalogen underwent significant lipid remodeling at sn-2 to also replenish other PlsEtns 16:0/x. No augmentation of PlsEtns 18:0/x or PlsEtns 18:1/x were detected, suggesting that a combination of 16:0, 18:0 and 18:1 ether lipid precursors may be needed to obtain the best potential clinical outcome for plasmalogen precursors in RCDP clinical trials.

The Pex7 hypomorphic mouse has been shown to possess approximately $50 \%$ reductions in plasmalogens, assayed by a procedure that does not distinguish the multiple plasmalogen species [9]. Our LC-MS/MS analyses also demonstrated an approximate 50\% decrease in cellular pools of plasmalogens but also detected much more dramatic decrements in DHA-containing plasmalogens in the eye and brain. These tissues are highly dependent upon DHA and DHA-containing plasmalogens $[15,16]$ and possess specific transport mechanisms to import plasmalogens and plasmalogen precursors $[17,18]$. Our studies with labeled PPI-1011 (PPI-1038) demonstrated that this ether lipid precursor is orally
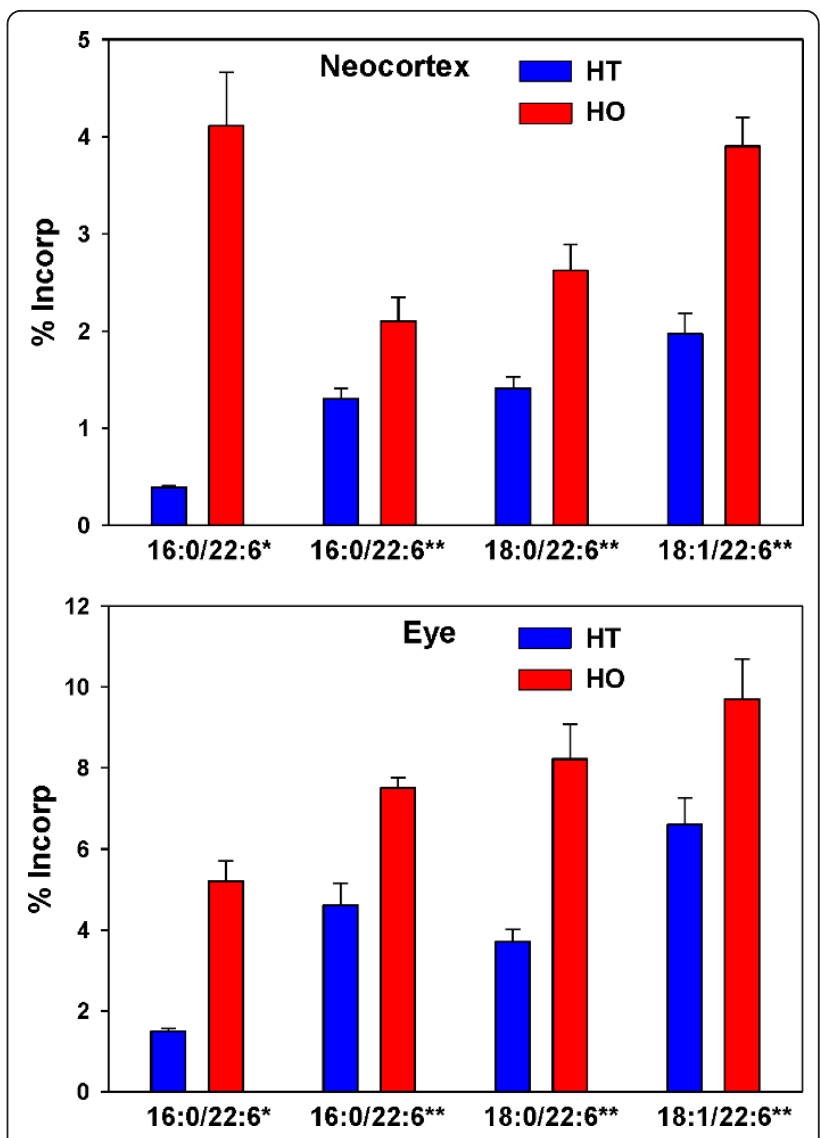

Figure 6 Incorporation of $\left[{ }^{13} \mathrm{C}_{6}\right]$ palmitic acid and $\left[{ }^{13} \mathrm{C}_{3}\right]$ glycerol (*) from PPI-1038 (100 mg/kg/day for 3 days) into PlsEtn 16:0/ 22:6 in the neocortex and eyes of Pex7 mice. Similarly the incorporation of $\left[{ }^{13} \mathrm{C}_{3}\right] \mathrm{DHA}\left({ }^{* *}\right)$ into PlsEtn 16:0/22:6, PlsEtn 18:0/22:6 and PIsEtn 18:1/22:6 is presented. $N=4$. Mean \pm SD. Increases in labeling in the Pex7 mice were significant in all cases $(p<0.01)$. HT, heterozygote controls; $\mathrm{HO}$, homozygotes. ${ }^{*}=\left[{ }^{13} \mathrm{C}_{16}\right]$ palmitic acid + $\left[{ }^{13} \mathrm{C}_{3}\right]$ glycerol labeled PIsEtn $\mathrm{x} / 22: 6 ;{ }^{* *}=\left[{ }^{13} \mathrm{C}_{3}\right] \mathrm{DHA}$ labeled PIsEn $\mathrm{x} /$ 22:6.

bioavailable and generates the target plasmalogen (PlsEtn 16:0/22:6; Figure 6) in a number of control mouse tissues. Our data further emphasize the importance of the liver in the synthesis of critical peroxisomedependent CNS plasmalogens, as previously shown for DHA [16]. In addition this plasmalogen synthesis from labeled PPI-1011 is augmented in Pex7 deficient mice. The lack of lipid remodeling at sn-1 again indicates that a cocktail of 16:0, 18:0 and 18:1 ether lipid precursors to obtain a therapeutic effect in RCDP may be needed.

Ethanolamine plasmalogen synthesis is complicated in that multiple cellular compartments are involved [19]. In the case of PMD, the combination of aberrant function of peroxisomes and the endoplasmic reticulum $[20,21]$ results in decrements in plasmalogens [7]. Our data with PMD lymphocytes demonstrate that this combination of cellular defects limits the ability of ether 


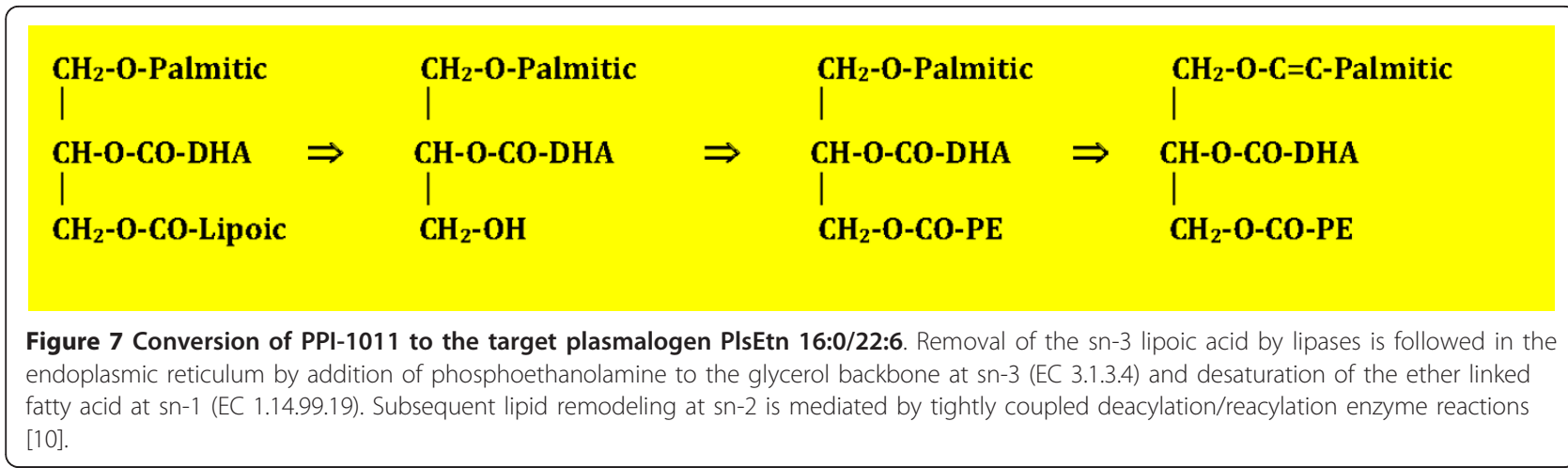

lipid precursors to resupply plasmalogens and that this is unlikely to be a fruitful therapeutic approach for PMD.

In summary, these data demonstrate that ether lipid precursors can bypass dysfunctional peroxisomes and replace critical plasmalogens in RCDP lymphocytes and in the Pex7 mouse model of RCDP1. These data also indicate that early and sustained supply of a combination of 16:0, 18:0 and 18:1 ether lipid precursors may be the optimal translational path for a clinical study. This is a hypothesis that we will first validate in the Pex7 mouse. Our data also suggest that plasmalogen replacement in PMD with ether lipid precursors is unlikely to be a viable strategy.

\section{List of abbreviations}

16:0: palmitic acid; 18:0: stearic acid; 18:1: oleic acid; 18:2: linoleic acid; 20:4: arachidonic acid; 22:6: docosahexaenoic acid (DHA); HO: homozygote; HT: heterozygote; PIsEtn: ethanolamine plasmalogen; PMD: Pelizaeus-Merzbacher disease; RCDP: rhizomelic chrondrodysplasia punctata.

\section{Acknowledgements}

TS was supported by a Canadian National Research Council postdoctoral fellowship. NB and WC were supported by the Montreal Children's Hospital Research Institute and the Montreal Children's Hospital Foundation Special Funds for Research in RCDP. The authors also would like to express their appreciation to the patients whom donated lymphocytes for research and the individuals with the foresight to establish the Coriell cell repository that allows researchers to investigate hypotheses of disease etiology at cellular and molecular levels.

\section{Author details}

'Dept. of Pharmacology, DeBusk College of Osteopathic Medicine, Lincoln Memorial University, 6965 Cumberland Gap Parkway, Harrogate, TN, 37752, USA. ${ }^{2}$ R\&D Dept., Phenomenome Discoveries Inc, 204-407 Downey Road, Saskatoon, SK, S7N 4L8, Canada. ${ }^{3}$ Depts. of Human Genetics and Pediatrics, McGill University-Montreal Children's Hospital Research Institute, 4060 SteCatherine West, PT-406.2, Montreal, QC, H3Z 2Z3, Canada.

\section{Authors' contributions}

All authors read and approved the manuscript. All authors participated in the study design, supervision of assay QA/QC and data interpretation. TS, GE, WJ, WC and PW performed experiments.

\section{Competing interests}

PW, AK, GE, TS and DG are all involved in the preclinical development of PPI-1011.
Received: 9 August 2011 Accepted: 18 October 2011

Published: 18 October 2011

\section{References}

1. White AL, Modaff P, Holland-Morris F, Pauli RM: Natural history of rhizomelic chondrodysplasia punctata. Am J Med Genet A 2003, 118A:332-42.

2. Brites $P$, Waterham HR, Wanders RJ: Functions and biosynthesis of plasmalogens in health and disease. Biochim Biophys Acta 2004, 1636:219-312.

3. Steinberg SJ, Dodt G, Raymond GV, Braverman NE, Moser AB, Moser HW: Peroxisome biogenesis disorders. Biochim Biophys Acta 2006, 1763:1733-48.

4. Nimmo G, Monsonego S, Descartes M, Franklin J, Steinberg S, Braverman N: Rhizomelic chrondrodysplasia punctata type 2 resulting from paternal isodisomy of chromosome 1. Am J Med Genet A 2010, 152A:1812-7.

5. Ofman R, Hettema EH, Hogenhout EM, Caruso U, Muijsers AO, Wanders RJ: Acyl-CoA:dihydroxyacetonephosphate acyltransferase: cloning of the human cDNA and resolution of the molecular basis in rhizomelic chondrodysplasia punctata type 2. Hum Mol Genet 1998, 7:847-53.

6. Purdue PE, Skoneczny M, Yang X, Zhang JW, Lazarow PB: Rhizomelic chondrodysplasia punctata, a peroxisomal biogenesis disorder caused by defects in Pex7p, a peroxisomal protein import receptor: a minireview. Neurochem Res 1999, 24:581-6.

7. Wood PL, Smith T, Pelzer L, Goodenowe DB: Targeted Metabolomic Analyses of Cellular Models of Pelizaeus-Merzbacher Disease Reveal Plasmalogen and Myo-Inositol Solute Carrier Dysfunction. Lipids in Health and Disease 2011, 10:102.

8. Singh I, Singh AK, Contreras MA: Peroxisomal dysfunction in inflammatory childhood white matter disorders: an unexpected contributor to neuropathology. J Child Neurol 2009, 24:1147-57.

9. Regis S, Grossi S, Corsolini F, Biancheri R, Filocamo M: PLP1 gene duplication causes overexpression and alteration of the PLP/DM20 splicing balance in fibroblasts from Pelizaeus-Merzbacher disease patients. Biochim Biophys Acta 2009, 1792:548-54.

10. Braverman N, Zhang R, Chen L, Nimmo G, Scheper S, Tran T, Chaudhury R, Moser A, Steinberg S: A Pex7 hypomorphic mouse model for plasmalogen deficiency affecting the lens and skeleton. Mol Genet Metab 2010, 99:408-16.

11. Thai TP, Rodemer C, Jauch A, Hunziker A, Moser A, Gorgas K, Just WW: Impaired membrane traffic in defective ether lipid biosynthesis. Hum Mol Genet 2001, 10:127-36.

12. Wood PL, Khan A, Mankidy R, Smith T, Goodenowe DB: Plasmalogen Deficit: A New and Testable Hypothesis for the Etiology of Alzheimer's Disease., Open Access in Alzheimers Disease- Book 2, ISBN 979-953-307$022-2$.

13. Goodenowe DB, Cook LL, Liu J, Lu Y, Jayasinghe DA, Ahiahonu PW, Heath D, Yamazaki Y, Flax J, Krenitsky KF, Sparks DL, Lerner A, Friedland RP, Kudo T, Kamino K, Morihara T, Takeda M, Wood PL: Peripheral ethanolamine plasmalogen deficiency: a logical causative factor in Alzheimer's disease and dementia. J Lipid Res 2007, 48:2485-98.

14. Wood PL, Mankidy R, Ritchie S, Heath D, Wood JA, Flax J, Goodenowe DB: Circulating plasmalogen levels and Alzheimer Disease Assessment Scale- 
Cognitive scores in Alzheimer patients. J Psychiatry Neurosci 2010, 35:59-62.

15. Hiratsuka S, Koizumi K, Ooba T, Yokosgoshi H: Effects of dietary docosahexaenoic acid connecting phospholipids on the learning ability and fatty acid composition of the brain. J Nutr Sci Vitaminol 2009, 55:374-380.

16. Scott BL, Bazan NG: Membrane docosahexaenoate is supplied to the developing brain and retina by the liver. Proc Natl Acad Sci USA 1989, 86:2903-2907.

17. Candela P, Gosselet F, Miller F, Buee-Scherrer V, Torpier G, Cecchelli R, Fenart L: Physiological pathway for low-density lipoproteins across the blood-brain barrier: transcytosis through brain capillary endothelial cells in vitro. Endothelium 2008, 15:254-64.

18. Polozova A, Gionfriddo E, Salem N Jr: Effect of docosahexaenoic acid on tissue targeting and metabolism of plasma lipoproteins. Prostaglandins Leukot Essent Fatty Acids 2006, 75:183-90.

19. Thoms $S$, Grønborg S, Gärtner J: Organelle interplay in peroxisomal disorders. Trends Mol Med 2009, 15:293-302.

20. Koizume S, Takizawa S, Fujita K, Aida N, Yamashita S, Miyagi Y, Osaka H: Aberrant trafficking of a proteolipid protein in a mild PelizaeusMerzbacher disease. Neuroscience 2006, 141:1861-9.

21. Simons M, Kramer EM, Macchi P, Rathke-Hartlieb S, Trotter J, Nave KA, Schulz JB: Overexpression of the myelin proteolipid protein leads to accumulation of cholesterol and proteolipid protein in endosomes/ lysosomes: implications for Pelizaeus-Merzbacher disease. J Cell Biol 2002, 157:327-36.

\section{doi:10.1186/1476-511X-10-182}

Cite this article as: Wood et al.: In vitro and in vivo plasmalogen replacement evaluations in rhizomelic chrondrodysplasia punctata and Pelizaeus-Merzbacher disease using PPI-1011, an ether lipid plasmalogen precursor. Lipids in Health and Disease 2011 10:182.

\section{Submit your next manuscript to BioMed Central and take full advantage of:}

- Convenient online submission

- Thorough peer review

- No space constraints or color figure charges

- Immediate publication on acceptance

- Inclusion in PubMed, CAS, Scopus and Google Scholar

- Research which is freely available for redistribution

Submit your manuscript at www.biomedcentral.com/submit
Biomed Central 